BULLETIN (New Series) OF THE

AMERICAN MATHEMATICAL SOCIETY

Volume 43, Number 4, October 2006, Pages 567-573

S 0273-0979(06)01130-X

Article electronically published on July 18, 2006

\title{
ABOUT THE COVER: EULER AND KÖNIGSBERG'S BRIDGES: A HISTORICAL VIEW
}

\author{
GERALD L. ALEXANDERSON
}

Graph theory almost certainly began when, in 1735, Leonhard Euler solved a popular puzzle about bridges. The East Prussian city of Königsberg (now Kaliningrad) occupies both banks of the River Pregel and an island, Kneiphof, which lies in the river at a point where it branches into two parts. There were seven bridges that spanned the various sections of the river, and the problem posed was this: could a person devise a path through Königsberg so that one could cross each of the seven bridges only once and return home? Long thought to be impossible, the first mathematical demonstration of this was presented by Euler to the members of the Petersburg Academy on August 26, 1735, and written up the following year under the title "Solutio Problematis ad Geometriam Situs Pertinentis (The solution to a problem relating to the geometry of position)" 2] in the proceedings of the Petersburg Academy (the Commentarii). The title page of this volume appears on the cover of this issue of the Bulletin.

This story is well-known, and the illustrations in Euler's paper are often reproduced in popular books on mathematics and in textbooks. Sandifer in [6] claims flatly that "The Königsberg Bridge Problem is Euler's most famous work," though scholars in other specialties (differential equations, complex analysis, calculus of variations, combinatorics, number theory, physics, naval architecture, music, ...) might disagree. N. L. Biggs, E. K. Lloyd, and R. J. Wilson in their history of graph theory [1] clearly view this paper of Euler's as seminal and remark: "The origins of graph theory are humble, even frivolous. Whereas many branches of mathematics were motivated by fundamental problems of calculation, motion, and measurement, the problems which led to the development of graph theory were often little more than puzzles, designed to test the ingenuity rather than to stimulate the imagination. But despite the apparent triviality of such puzzles, they captured the interest of mathematicians, with the result that graph theory has become a subject rich in theoretical results of a surprising variety and depth." Euler provides only a necessary condition, not a sufficient condition, for solving the problem. But he does treat more than the original problem by beginning a generalization to two islands and four rivers, as is illustrated in the plate accompanying the original paper (Figure 1).

In this renowned paper Euler does not get around to stating the problem until the second page. On the first he states the reason for being interested in the problemit was an example of a class of problems he attributes to Leibniz as belonging to something Leibniz called "geometry of position." Euler says that "this branch is concerned only with the determination of position and its properties; it does not 
involve distances, nor calculations made with them." So, he goes on to say, when "a problem was recently mentioned, which seemed geometrical but was so constructed that it did not require the measurement of distances, nor did calculation help at all, I had no doubt that it was concerned with the geometry of position."

This was an about-face for Euler, since earlier he had complained in a letter to Carl Leonhard Ehler, mayor of Danzig, that the Königsberg problem "bears little relationship to mathematics ... for the solution is based on reason alone, and its discovery does not depend on any mathematical principle." He claimed that he was "ignorant as to what this new discipline [geometry of position] involves, and as to which types of problem Leibniz and [Christian] Wolff expected to see expressed in this way" [5. To the modern reader, though, the "geometry of position" sounds a lot like topology, but more on that later.

The title of the Biggs, Lloyd and Wilson volume is Graph Theory/1736-1936, and it is interesting that the authors refer to 1736 rather than the date of Euler's first report. Possibly the later date was chosen because by using 1736 they were able to add to their account the publication in 1936 of the first full-length book on graph theory by Dénes König.

They could as well have chosen the starting date as 1741, however, since the publication of Euler's paper did not occur till then. Backlogs were apparently a problem even in the 18th century, but perhaps they were more of a problem for Euler than most since he was so prolific. His work practically dominated the proceedings of the Petersburg Academy even after he moved to Berlin in 1740 and subsequently when he returned to St. Petersburg in 1766. In the 1741 volume of the Commentarii the articles were split up into three "classes" (Mathematics, Physics, and History) with another category of "observations" on astronomy and meteorology. Within the Mathematics section, eleven of the thirteen articles were by Euler. The other two were by Daniel Bernoulli. It is interesting to note the company this first article on graph theory keeps in this volume, which includes the articles that Euler wrote in 1735 and 1736. Five of his papers are on series or properties of curves. One is on number theory, one on calculus of variations, one on elliptic integrals, and two on astronomy or physics. And then there's this rather amazing paper on graph theory. Not surprisingly, both of Bernoulli's papers are on hydrodynamics. Here's Euler's list:

- Methodus universalis serierum convergentium summas quam proxime inveniendi (A universal method for finding sums of convergent series approximately)

- Inventio summae cuiusque seriei ex dato termino generali (Finding the sum of a series from a given general term)

- Investigatio binarum curvarum, quarum arcus eidem abscissae respondentes summam algebraicam constituant (An investigation of pairs of curves whose arcs that correspond to the same abscissa constitute an algebraic sum)

- De Oscillationibus fili flexilis quotcunque pondusculis onusti (On the oscillation of a flexible wire weighted with arbitrarily many small weights)

- Methodus computandi aequationem meridiei (A method for computing the equation of a meridian)

- De constructione aequationum ope motus tractorii, aliisque ad methodum tangentium inversam pertinentibus (On the construction of equations using a dragging motion and on other things pertinent to the inverse method of tangents) 
- Solutio problematum rectificationem ellipsis requirentium (The solution of a problem requiring the rectification of an ellipse)

- Theorematum quorundam ad numeros primos spectantium demonstratio (A proof of certain theorems regarding prime numbers)

- Methodus universalis series summandi ulterius promota (A universal method for summation of series, further developed)

- Curvarum maximi minimive proprietate gaudentium inventio nova et facilis (A new and easy way of finding curves with a maximum or minimum property)

The two papers by Daniel Bernoulli were:

- De legibus quibusdam mechanicis, quas natura constanter affectat, nondum descriptis, earumque usu hydrodynamico, pro determinanda vi venae aqueae contra planum incurrentis (On certain mechanical laws, which nature constantly applies, not yet described, and their hydrodynamic use for determining the force of a jet of water striking a plane)

- Dissertationis de legibus mechanicis nondum descriptis pars altera, in qua legum istarum in prima parte expositarum usus hydrodynamicus ostenditur (The second part of a treatise on mechanical laws not yet described, in which there is shown the hydrodynamic use of these laws presented in the first part)

Most of these papers of Euler's from 1735-36 are not of the first rank. But in case anyone should conclude that in the year in which Euler developed graph theoretic techniques to solve the puzzle of the Königsberg bridges he was not having a good year, one should keep in mind that in 1736 he also published one of his monumental books, his Mechanica Sive Motus Scientia Analytice. One of the papers mentioned above, "Theorematum quorundam ad numeros primos spectantium demonstratio", contains the proof of Fermat's Little Theorem in number theory (hinted at in a paper of Euler's as early as 1732 and thereafter, in more generality, referred to as Euler's Theorem - one of many such). A few other extremely influential papers missed being in the volume by only a year or two. His solution of the Basel Problem (finding the value of $\zeta(2)$ ), "De summus serierum reciprocarum (On the sums of series of reciprocals)", had been published in 1740 in Volume 7 of the Commentarii. His groundbreaking theorem on continued fractions, "De fractionibus continuis dissertatio (A treatise on continued fractions)", was written in 1737 and published in Volume 9 of the Commentarii, which came out in 1744, as was his "Variae observationes circa series infinitas (Various observations on infinite series)", which provided the product-sum formula for what later was called the Riemann $\zeta$-function.

Euler's papers in Volume 8 of the Commentarii are sometimes not in what we would necessarily classify as mathematics today. As one can see from the titles, two are close to astronomy or physics. But then again, some of the articles in the Physics Section look to us a lot like botany or physiology.

That Euler wrote almost all of the mathematical papers that appeared in Volume 8 of the Commentarii is not surprising. In his first period in St. Petersburg, up till 1741, he announced findings to the Academy about ten times per year, far surpassing other contributors, who averaged one to five reports. In the second half of 1735, 21 of 23 meetings of the "Mathematical Conference" were reviews or talks by Euler, so the volume of the Commentarii for 1735-36 gives a fairly accurate picture of the spread of Euler's interests and the way he dominated the mathematical section of the Commentarii in those years. During the 25 years he spent in 
Berlin, roughly half of his papers, approximately 100, were sent for publication to St. Petersburg, where he maintained close ties to the Academy. Overwhelmingly, Euler's contributions outnumbered submissions by others, and even when the work of other mathematicians appeared, the authors were often Euler's students. He usually sent the papers in batches of five or six, but in the spring of 1772 , much later than the year we are concentrating on here, he sent thirteen manuscripts in a single batch 4 .

Lest one conclude that the Königsberg bridge problem was Euler's only contribution to graph theory, one should keep in mind that, as Sandifer points out in 6], Euler presented in 1759 (and published in 1766) his "Solution d'une question curieuse que ne paroît soumise à aucune analyse (A solution to a curious problem that does not appear to be subjected to any analysis)" [3], the solution to the knight's tour, which was a precursor to Hamiltonian circuits, something still inspiring research today.

We already noted that the Königsberg paper could be viewed as a pioneering paper in topology. But the better-known precursors of topology among Euler's works are the related papers "Elementa Doctrinae Solidorum (Elements of the doctrine of solids)" and "Demonstratio nonnullarum insignium proprietatum, quibus solida hedris planis inclusa sunt praedita (Proof of some of the properties of solid bodies enclosed by planes)" in the Novi Commentarii Academiae Scientiarum Imperialis Petropolitanae 4 (1758), 109-140, 140-160. These papers contained the first appearance of Euler's formula for polyhedra.

Whether Euler's paper on the Königsberg problem or his knight's tour paper constitutes the first publication in what we now call topology is an open question. Gauss wrote in 1833 that, regrettably, little of value had been done to address Leibniz's concern over problems in the "geometry of position," other than some pieces by Euler and A.-T. Vandermonde. It was not clear whether Gauss was referring to the Königsberg problem or the knight's tour. Johann Benedict Listing (a student of Gauss's who suggested the word "topology" to cover these problems described by Leibniz) claimed that Gauss was citing not the Königsberg problem but the knight's tour [1]. Others disagreed. But that's another story.

\section{ACKNOWLEDGMENT}

I am grateful to my colleague, Dennis C. Smolarski, S.J., who provided invaluable assistance with the translation of the Latin titles of Euler's papers.

\section{REFERENCES}

1. Norman L. Biggs, E. Keith Lloyd, and Robin J. Wilson, Graph Theory/1736-1936, Clarendon Press, Oxford, 1976, pp. 1-3, 21-22. MR0444418(56:2771)

2. Leonhard Euler, Solutio Problematis ad Geometriam Situs Pertinentis, Commentarii Academiae Scientiarum Imperialis Petropolitanae 8 (1741), 128-140 = Opera Omnia (1), Vol. 7 , $1-10$.

3. Leonhard Euler, Solution d'une question curieuse que ne paroît soumise à aucune analyse, Mém. Acad. Sci. Berlin 15 (1766), 310-337 = Opera Omnia (1), Vol. 7, 26-56.

4. Yu. Kh. Kopelevich, Leonhard Euler: Active and honored member of the Petersburg Academy of Sciences (Russian), in Development of the Ideas of Leonhard Euler and Modern Science: A Collection of Papers, N. N. Bogolyubov, G. K. Mikhallov, and A. P. Yushkevich, eds. (Russian), "Nauka", Moscow, 1988, 47-59. MR0952155 
5. Horst Sachs, Michael Stiebitz, and Robin J. Wilson, An historical note: Euler's Königsberg letters, J. Graph Theory 12, no. 1 (1988), 133-139. MR0928743 (89c:01027)

6. Sandifer, C. Edward, The Early Works of Euler, Mathematical Association of America, Washington, DC (to appear).

Department of Mathematics and Computer Science, Santa Clara University, Santa Clara, California 95053

E-mail address: galexand@math.scu.edu

EDITOR'S NOTE: We are very grateful to Gerald L. Alexanderson for permission to use the image on the cover and the figure from the article by L. Euler (Figure 1). 

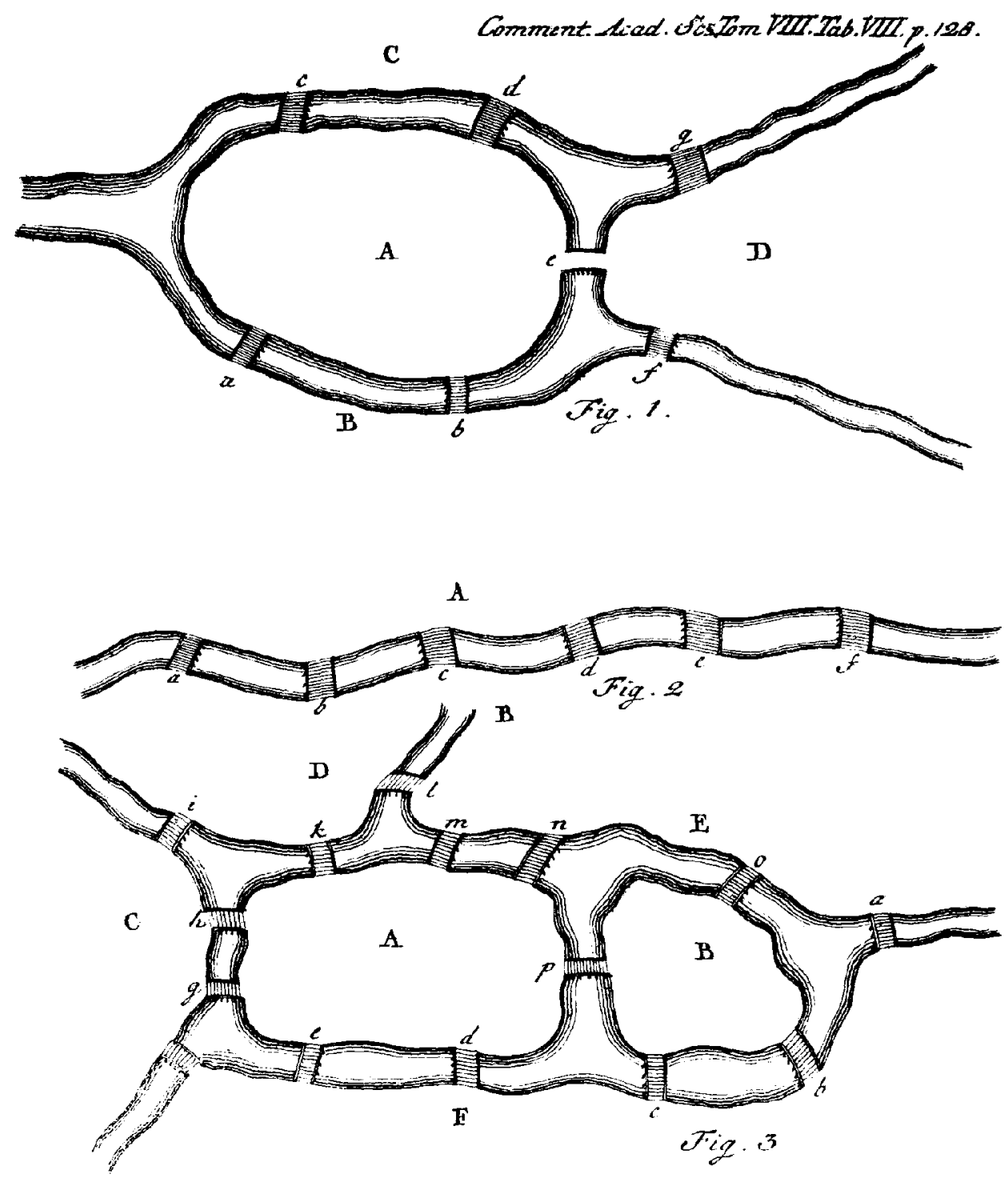

FiguRE 1. The engravings illustrating Euler's 1736 paper on the bridges of Königsberg. 


\section{COMMENTARII} ACADEMIAE SCI E N T I A R V M

IMPERIALIS PETROPOLITANAE.
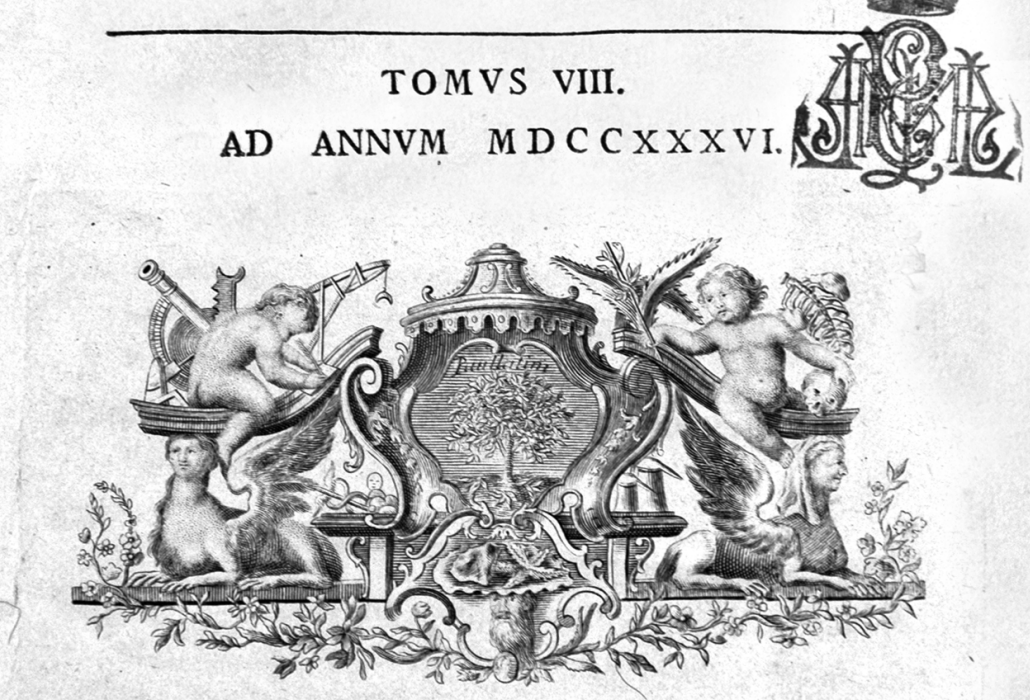

PETROPOLI,

TYPIS ACADEMIAE clobocxLI. 